\title{
Elementi formalnih postupaka u zaumnom pesničkom eksperimentu
}

\begin{abstract}
Latifić Amra, Elementi formalnih postupaka u zaumnom pesničkom eksperimen$t u$ (Elements of the Formal Procedures in Zaum Poetic Experiment). "Poznańskie Studia Slawistyczne" 13. Poznań 2017. Publishing House of the Poznań Society for the Advancement of the Arts and Sciences, pp. 81-94. ISSN 2084-3011.

The paper analyzes the elements and strategies of Russian formalism applied to the Russian avantgarde zaum poetic experiment of Alexei Kruchenykh and Viktor Khlebnikov. In futuristic tendencies to create a trans-rational language or zaum language lies the idea of a new voice, sounds and semantic meaning. According to Russian poets the new semantic meaning of the word is obtained only in the process of performing a poem. Also, according to Russian formalism, sound of poem, in the performing process, has its own independent meaning. In this sense zaum experiment in its printed form does not possess a fixed resolution of meanings, but only has potential of meanings. The function of fixed forms, that during the process of performing is to form a new movable semantic meaning.
\end{abstract}

KEYWORDS: zaum; formalism; poetry; Russian avantgarde; form; function

Zaumni pesnički eksperiment je umetnička pojava u okviru ruske književne avangarde. U evropskim avangardnim pesničkim pokretima dolazi do razaranja reči prirodnog govora na primarne nekomunikativne iskaze (glasovi, proizvoljno kombinovane reči, slova ili slogovi). U tom smislu Filipo Tomazo Marineti sopstvenim glasom izvodi onomatopejsku artiljeriju u poemi Zang tumb tumb. Ruski avangardni pesnički eksperiment vezuje se za pojavu ruskog futurizma ili kubofuturizma krajem desetih godina XX veka. Termin futurizam preuzet je od Marinetija. Međutim, ruski futurizam se bitno razlikovao od italijanskog. Aleksandar Flaker objašnjava:

Polazeći od srodne parole „oslobođene reči” (Marinetti) ili „,reči kao takve” (ruske skupine), ruski pesnici ne ostaju na onomatopeičnoj zvukovnoj i vizualnoj reprodukciji pojava gradske civilizacije, već grade potpunije modele suodnosa čoveka, stvari 
i kozmosa, (...) razbijaju analitički i samu reč na njene sastavne delove (Hlebnjikov) ili pak eksperimentišu s paraleksičkim, alogičnim ,jezikom” (Hlebnjikov, Kručonih), približavajući se tako rezultatima dadaističke i nadrealističke poetike (Flaker, 1984, 38).

U atmosferi predoktobarske Rusije spone između likovne i književne avangarde bile su veoma čvrste, gotovo da su se međusobno uslovljavale. Logika jezičkog formalizma u književnosti postaje dominantna u slikarstvu, a čista forma oslobođena semantičke logike u slikarstvu postaje element književnih eksperimenata.

Interknjiževni i interlikovni odnosi kao dominantni procesi pojavili su se i u jugoslovenskom kontekstu pojavom zenitizma dvadesetih godina prošlog veka. Vida Golubović ističe naročit značaj Branka Ve Poljanskog koji dekonstruiše stihovnu strukturu odgovarajućim grafičkim oblikovanjima poetskog stiha. Golubović piše da poeziju Poljanskog karakteriše nekoliko elemenata: „Pomeranje konstruktivnih granica stiha («stihovni sdvig»), odnosno raščlanjivanje njegovih struktura i segmentovanje po principu opozicija, sinonimičkih odnosa, ponavljanja, kao i odsustvo sintaksičkih relacija, umesto kojih se uspostavljaju relativno samostalni leksički nizovi” (Golubović u Flaker, 1985, 167). Kao primer Golubović navodi pesmu Poljanskog U znaku kruga, gde autor koristi metod „stihovnog sdviga", te sprovodi intermedijalnu korelaciju slike i stiha, težeći ka sintagmatici slikarskog dela.

Težnja ka teorijskom istraživanju forme, kao i izučavanje pojava intermedijalnosti i međusobno ukrštanje različitih disciplina obeležila su čitav XX vek. Forme prikazivanja i interpretiranja sveta ne zavise od prikazivanja spoljašnjeg sveta ili zakona prirode i ljudskog iskustva, nego od formalnih, jezičkih, konceptualnih i logičkih pravila. U ovakvoj teorijskoj klimi formalizam postaje jedan od najuticajnijih teorijskih pravaca XX veka. Ruski formalizam, utemeljen kao književna teorija (1915-1928) uspešno je primenjivan i na likovne umetnosti, film i pozorište. On uspostavlja novi pojam forme (jezičke forme), koji je zatim primenjen na analizu postupaka stvaranja umetničkog dela i njegovog funkcionisanja u kulturi i svetu. Dubravka Đurić ističe da „radikalne pesničke prakse u prvi plan stavljaju formalne elemente" (Đurić, 2002, 110).

Eksperimentalni pesnički rad nad zaumnim delom prolazi formalni proces stvaranja tako što umetnik/pesnik svesnom odlukom organizuje 
pisani pesnički materijal (materiju, slova, buduće telo pesničkog objekta) time što ga prvo fiksira u pisanoj fazi. U izvođačkoj fazi, odnosno u daljoj interpretaciji, oformljeni vizuelni poredak zaumne strukture pesnik tokom procesa izvođenja uvodi u igru zavođenja. Kombinatorika elemenata fiksirane formacije pisane pesničke zaumne strukture strategijom transformacije (čin izvođenja) je učinila da konkretni objekat počinje da postoji kao imaginarni efekat. Funkcija vizuelne strukture je da oko i sluh posmatrača i slušaoca prilikom samog izvođenja zaumne pesme podvrgne logici koja se ne može doživeti kao konkretna logika, odnosno kao racionalni konsenzus. Cilj glasovnog izvođenja je novo semantičko značenje. Dakle, funkcija fiksirane forme je da u procesu samog izvođenja formira nova pokretljiva semantička značenja.

Osnovne ideje ruske futurističke poezije predstavljala su eksperimentalna rešenja Alekseja Kručoniha i Viktora Hlebnjikova. U futurističkoj težnji da se stvori transracionalni ili zaumni jezik leži ideja o novom govornom, semantičkom značenju reči. Zaumna poezija oslanja se na intuiciju i transracionalnu retoriku. Kručonih piše: „Ono što doživimo ne možemo izreći rečima (reči i pojmovi su okoštali) - reči su mučne - one su gnoseološki prazne. Otuda stremljenje ka zaumnom, slobodnom jeziku. Takvom načinu razmišljanja čovek pribegava u značajnim trenucima života” (Кручёных, 2001, 19). Tokom stvaranja zaumnog jezika Kručonih se interesovao za čisto lingvističke probleme. Povodeći se lingvističkom logikom dolazi do potpune destrukcije lingvističkog oblika unutar same reči. Kručonih je preko zaumnog jezika favorizovao ideju o jeziku nove poezije, čije se značenje bazira isključivo na čistom zvukovnom segmentu nove reči . Teksturu reči on posmatra kroz njene zvukovne i verbalne karakteristike. Pored verbalne i zvukovne teksture, identifikovao je i silabičku, ritmičku, semantičku, sintaksičku, grafičku i leksičku teksturu reči. U tom smislu uvodi pojam samodovoljne reči, odnosno reči kao takve. Pod pojmom samodovoljnost Kručonih podrazumeva oslobađanje reči od njenog podređenog značenja. Oslobađanjem podređenog značenja, poetska artikulacija postaje slobodna i samostalna.

U osnovici stvaranja zaumnog jezičkog eksperimenta Kručonih postavlja vizuelno konstruisane pesme bez precizne topografije. Štampani zaumni tekst predstavlja formalni uzorak mogućnosti poetskog značenja. Značenjske mogućnosti štampanog (fiksiranog) teksta realizuju se efektima 
materijalizacije glasovnog govora odnosno efektima izgovaranja samog teksta. U tom smislu zaumni eksperiment u svojoj štampanoj formi ne poseduje razrešenje značenja, već samo punktuira potencijalna značenja. Efekat glasa postaje nosilac osnovnog značenja, a štampani tekst postaje njegov potencijalni objekat. U pitanju su antiekspresivne, mehaničke konstrukcije izvođenja govora. Izgovorena pesnička zaumna jedinica postaje medijsko, prostorno $i$ vremensko događanje. Time zaumni eksperiment razvija vandijaloški, nenarativni, ambijentalni diskurs (scenografski, koreografski, multimedijalni).

Kombinacija suglasnika u zaumnom eksperimentu predstavlja jezik lišen fiksiranog pojmovnog značenja. Samoglasnici, kao najzvučniji glasovi, predstavljaju najsavršeniji jezik svojom jednostavnošću. Maksimalnom redukcijom Kručonih se vraća na jezik prvobitne ljudske zajednice. Zaumni eksperimentalni zvuk je u artificijelnom i specifično konstruisanom kretanju u odnosu na svoju štampanu verziju. Tekstualna/štampana proizvodnja pesme stvara indeksna značenja koja pokreću doslovan čin izgovora samoglasnika i suglasnika u zaumnom činu. Zaumna pesma prikazana štampanom formom svoje značenje dobija tek disperzivnim zvučanjem u prostoru.

$\begin{array}{ccc}\text { a } & \text { e } & \text { u } \\ \text { e } & \text { e } & \text { u } \\ \text { iii } & & \text { e }\end{array}$

Kručonih u predstavljenoj zaumnoj pesmi ne daje nikakve indikacije u kojoj se mogu prepoznati tragovi utilitarnog govornog jezika. Vizuelno, Kručonih pravi geometrijsko oblikovanje zaumne pesme. Geometrijsko oblikovanje će u izvođenju usloviti organizovanost glasovnog zvučanja u prostoru. Glavni i najdominantniji zvučni elementi izvođenja pesme nalaze se na tačkama geometrijskih konstrukcija. Geometrijsku formu pesmi daje spoljni kvadrat slike $(\mathrm{a}-\mathrm{u}-\mathrm{e}-\mathrm{iii})$. Osnova kvadrata leži na trouglu (iii - e e), koji mu u statičkom smislu daje neograničenu čvrstinu osnove. Kručonih vizuelno namerno pravi «ispust» na kvadratskoj osnovi u obliku trougla, polazeći od činjenice da je trougao jedina geometrijska figura koja ne trpi deformacije usled dejstva spoljnih sila. Cela figura pesme leži na dve tačke: iii i e. Očigledno je da spoljnu, vizuelnu stabilnost figuri daju nesimetrična raspodela samoglasničkih snaga: $i i i$ prema $e$. Početni samoglasnik pesme je 
samoglasnik $a$, kao prvi samoglasnik koji čovek izgovori po rođenju (reč „mama”, slična je gotovo u svim jezicima). Čvrstinu konstrukciji daje glas $e$, koji se nalazi na svim stranicama i dijagonalama kvadrata. Samoglasnik $e$ takođe se nalazi i na svim temenima trouglova. Geometrijska konstrukcija upravo u svojoj fiksiranosti i čvrstini forme, glasovnom zvučanju daje potpunu oslobođenost u artikulaciji. Na takvoj geometrijskoj konstrukciji moguća je glasovna improvizacija: čitanje zaumne pesme može se realizovati u svim pravcima. Oslonci svake varijante glasovne improvizacije su tačke fiksiranih formalnih geometrijskih konstrukcija. Zaumna pesma dobija svoje značenje zvučanjem u prostoru.

U libretu za operu Pobeda nad suncem, Kručonih u drugom činu piše glasovnu pesmu. Nakon što je jedan od glavnih likova opere, avijatičar, preživeo udes, poručuje publici:

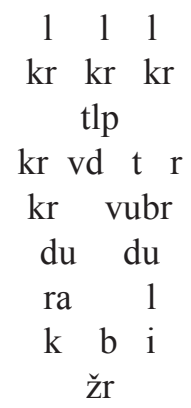

Ova pesma nije koncipirana po pravilima gramatike i jezičke logike. Rosemarie Ziegler piše:

U vreme saradnje sa slikarima koji su utemeljili bespredmetnu umetnost (Malevič, Rozanova), Kručonih je motivisao zaum idejama i postupcima tog pravca (u poeziji se to očituje kao zamena retka samostalnim slovima, rastvaranje slova u grafički crtež i boju, rastvaranje reči u zvučne ,mase”, kao ,ekonomija” umetničkih sredstava) (Ziegler u Flaker, 1985, 195).

U navedenoj pesmi Kručonih koristi deklamatorsko čitanje poezije koje bitno utiče na recepciju fonetike i samog govora, a od formalnih postupaka eksperimentiše sa ortografijom, sintaksom i slučajnošću. Ova pesma svoju materijalnu dimenziju proširuje u vizuelni prostor i time 
pokazuje direktne karakteristike vizuelne poezije. Samim tim, pesma više ne predstavlja fiksiran i stabilan lingvistički objekat, a njeno čitanje postaje nezavisan medij. Tumačeći performativnost vizuelne poezije Charles Bernstein piše o fluidnosti i umnožavanju njenih formi. Ovim povodom Dubravka Đurić objašniava datu Bernsteinovu teoriju:

Charles Bernstein piše da je performativna dimenzija poezije povezana sa vizuelnom i konceptualnom umetnošću i vizuelnom poezijom, koje su zasnovane na tekstu, ali performativnu i materijalnu dimenziju književnog teksta proširuju u vizuelni prostor. Pesma koja postoji kao izvođački događaj a ne samo kao tekst, „pluralni je događaj” i ne može se izjednačiti ni sa jednom grafičkom ili performativnom realizacijom, niti je skup svih njih. Čitanje poezije odupire se autoritetu teksta. Pesma više nije fiksan, stabilan i konačan lingvistički objekat. Kada pesnici čitaju svoju poeziju, destabilizuju je, ona postaje fluidnija, a njene pojavne forme se umnožavaju (Bernstein to naziva pluriformom /pluriform/). Čitanje poezije nije podređeno ,prethodno" napisanom tekstu, već je odvojen medij po sebi (Đurić, 2002, 152).

Hlebnjikovljev zaumni rečnik predstavlja proces sopstvenog samokomentarisanja i pre svega objašnjenja forme sopstvenog diskursa. Koristeći zaumni eksperminent Hlebnjikov se lišava kontekstualne interpretativne zavisnosti, koju je posedovala tradicionalna književnost. Svoju strategiju sprovodi dosledno i strogo, formulišući kroz poeziju kompletan teorijski diskurs. Na tom putu Hlebnjikov potpuno briše sve granice između poezije i teorije: poezija postaje teorija i obrnuto. Po svojoj formi zaum je potpuni avangardistički eksperiment: on je autonoman, jezički zatvoren i predstavlja individualnu utopiju. Nils Ake Nilsson ističe da je Hlebnjikov pre svega stvarao nove jezičke kovanice. Nilsson pravi poređenje italijanskog i Hlebnjikovljevog futurizma i piše:

Talijanski je futurizam preporučivao upotrebu onomatopeje i „rušenje sintakse” za stvaranje poezije koja bi odgovarala novom načinu modernog društva. Hlebnjikov je odabrao drugačiji način: nije napao strukturu rečenice ili sintakse, već samu reč. Razbijanjem utemeljenog skupa prefiksa i sufiksa, zamenjujuči ih drugim, stvorio je rusku varijantu parole in liberta koja nije bila povezana s futurističkom idejom ,telegrafskog jezika" (Nilsson u Flaker, 1990, 215).

Carla Solivetti naročito naglašava da je Hlebnjikovljev pesnički eksperiment upravo značajan zbog mogućnosti najrazličitijeg tumačenja reči: „Celokupno stvaralaštvo reči Hlebnjikova, njegovi neologizmi, zaumni i zvezdani jezik, «azbuka uma», samo je pokušaj vertikalnog razvoja reči, 
njenog oslobađanja od uzakonjenog ropstva koje koči dinamičnost i izražajnost jezika" (Solivetti u Flaker, 1985, 233). Solivetti takođe ističe da jezičkom ,azbukom uma” Hlebnjikov nastoji da dokaže kosmičku dimenziju samog jezika: „Jezik je filter koji skuplja sve napetosti sveta i kosmičke odnose" (Solivetti u Flaker, 1985, 228). Svi eksperimentalni pokušaji Hlebnjikova kretali su se ka ideji da se zvuku koji se širi u prostoru i vremenu prida maksimalna slikovitost koja će proširiti poetsku semantiku.

Hlebnjikov je često dolazio do različitih zaključaka o jedinstvenim urođenostima jezičkih pojava u svim jezicima sveta. To je bio njegov teorijski put u zaumni jezik. Hlebnjikov piše: „Kada sam uvideo da su korenovi samo privid, da su iza njih strune azbuke, moj drugi odnos prema reči jeste nalaženje jedinstva svetskih jezika uopšte, jedinstva zasnovanog na jedinicama azbuke. Put u zaumni jezik sveta" (Hlebnjikov prema Ivanov, 2003, 127). Traganje za „„čistom” rečju svedeno je na oslobođenje reči od svakodnevnog automatizma, od upotrebnog konteksta, na otkrivanje njene unutrašnje fleksije. Hlebnjikov tvrdi da postoji veliki broj osnovnih jedinica azbuke od kojih polazi svaki jezik. Slobodna kombinacija tih zvukova stvara novu semantiku. Jezike treba razložiti na njihove osnovne jedinice i stvoriti od takve glasovne materije pravilan sistem: „Zakoni prostih tela azbuke isti su za porodice srodnih jezika" (Hlebnjikov 1964, 27). Svođenjem reči na njen minimum, odnosno „ogoljavanjem” korena reči, Hlebnjikov namerno narušava semantičku i sintaksičku ravnotežu, intenzivira unutrašnju fleksiju reči, obilato se služi zvučnim ponavljanjem, naročito aliteracijom, osećajući suglasnik mnogo valentnijim i ritmički i zvukovno efikasnijim. U najčešćoj njegovoj rimi - metatezi, suglasnici su znatno valentniji u odnosu na samoglasnike. Roman Jakobson smatra da je ovim postupkom Hlebnjikov nosilac tendencije u modernoj ruskoj poeziji koja se manifestuje u udaljavanju od nekadašnje ,semantičke, sintaktičke i morfološke simetrije ka sintaktičkoj asimetriji sprva, ka morfološkoj asimetriji potom" (Hlebnjikov 1964, 27). Suglasnicima Hlebnjikov pored zvučne efikasnosti pridaje i utopijsku funkciju: suglasnik „L” predstavlja stremljenje uvis, a suglasnici „G” i „R” breme sudbine dve zemlje:

Ispalo je „G” Germanii
I Rusa „R” je palo
I vidim „L” u magli ja... 
Carla Solivetti navodi: „Slovom «L» počinju reči libertas i ljubov, Lenjin, Lunačarski i Ladomir, budući svet sloge i harmonije (...) Slovo «L» u azbuci uma predstavlja stremljenje uvis, L odgovara imaginarnom broju, matematičkom simbolu slobode" (Solivetti u Flaker, 1985, 228).

Kao još jedan od postupaka, da bi ostvario poetsku tenziju, Hlebnjikov upotrebljava smisaona pomeranja (rus. сдвигu). Postupak „sdviga” koristi i Kručonih, a u stvaralačkom pesničkom procesu vezuje ga za slučajnost. Rosemarie Ziegler navodi: „Kručonih je motivisao «sdvig» dinamizmom, kretanjem, unutrašnjim i vanjskim doživljavanjem. (...) Kasnije se oslanjao i na teoriju formalista o poeziji kao deformaciji normalnog jezika" (Ziegler u Flaker, 1985, 196). Ovim postupkom su pesnički jezici Kručoniha i Hlebnjikova orijentisani na vlastiti leksički kod. Udaljenost između adresanta i adresata, između autorovog i recipijentovog prirodnog jezičkog koda, uslovljava situaciju u kojoj dolazi do velike količine autodekodirajućih iskaza, definicija, aksioma i drugih sfera vlasitog jezika. U tom smislu Hlebnjikov piše da ,postoji put da se zaumni jezik učini razumnim!" (Hlebnjikov prema Oraić, 1985, 19). Taj put je upravo predstavljao glosarsku funkciju pesničkog jezika. Ako bismo pokušali da uspostavimo kodiranje poezije Hlebnjikova preko Jakobsonovog modela, onda bi se ono baziralo na sintaksičkoj i morfološkoj asimetriji u kojoj recipijent autodekodira zaumni iskaz autora. Autodekodiranje vrši se u okvirima individualne mreže asocijacija. Osnovni model komunikacije predstavio je Jakobson na modelu iz 1964. godine:

Kontekst

Saopštenje

Adresant Adresat

Kontekst

Kod

Ovaj model komunikacije, poučen eksperimentima ruskih futurista i formalista, razvio je Jurij Lotman (Ю.М. Лотман) u drugoj polovini $\mathrm{XX}$ veka. Interesovala ga je prvenstveno formalna struktura pesme, njen zvukovni i ritmički sistem, preko koga je pronalazio značenja. Zaumni eksperimenti poslužili su mu kao ideja za proučavanje poetskog ritmičkog sistema. Naravno, Lotman je ostao u granicama govornog, 
maternjeg jezika. Ostaci ideja zauma, koji je predstavljao pesnikovu misaonu autorefleksiju preko formalnog procesa autodekodiranja jezika i metajezika, mogu se naći i kod Lotmanovog modela autokomunikacije. Pošiljalac informacije, po Jakobsonovom modelu iz 1964. godine, adresant, da bi preneo neku informaciju treba da saopšti primaocu informacije, adresatu, kroz određeni kod. Ovaj model Lotman postavlja na apstraktniji nivo i tvrdi da je moguće odrediti dva kanala komunikacije. Najčešće se upotrebljava JA-ON. U ovom komunikacijskom smeru JA predstavlja subjekt tj. nosioca informacije, adresanta, a ON-objekt, primaoca, adresata. Postoji i drugi pravac informacije koji bi bilo moguće predstaviti preko modela JA-JA. To je slučaj kada se subjekat obraća samom sebi i predstavlja autokomunikaciju. Autokomunikacija je proces koji nastaje iz recipijentovog autodekodiranja zaumne pesme. Model JA-JA nastaje $\mathrm{u}$ autodekodiranju zaumnog iskaza. Dalje u ogledu Lotman tvrdi da su metrika i zvukovna sfera teksta najtipičniji primer unutrašnjeg monologa čoveka. Na zvučanju fragmenata jezičkih sklopova pesnici zauma su takođe bazirali ontološko značenje stvarnosti. Zvuk je i kod Lotmana i kod zaumnih pesnika predstavljao osnovu za modelovanje sveta i stvaranje novog značenja i nove funkcije pesničkih elemenata. Na zvučanju zaumnih jedinica nastaje proces autokomunikacije.Zaumni jezik se vraćao na atomske arhijedinice uma, te je procesom dekonstrukcije govornog jezika konstruisao predsimboličko značenje posebnih, pojedinačnih jedinica arhijezika. U pitanju je redukcija naracije na osnovnu, pramateriju jezika, znaka. Dokazuje se da reč, slovo ili znak poseduju istu onu fenomenološku složenost kao i boja za slikara, glina za vajara itd. Razbijanje i redukcija logike prirodnog govora, regulisanog normama utilitarnog opštenja, pokazuje potencijalnu beskonačnost teksta. Hlebnjikovljev ili Kručonihov postupak zauma stvara prostor za beskonačan razvoj jezičkih generativnih moći. Razvoj moći jezika upravo leži u funkciji fiksirane vizuelne forme koja kroz proces izgovaranja/izvođenja stvara beskonačnost značenja. Kručonih piše: „Uvođenjem novih reči donosim novi sadržaj gde sve počinje da klizi (da se pomera)" (Kručonih prema Markov, 1968, 131). Novodolazeća značenja formiraju se na nereferencijalnim autonomnim strukturama jezika.

Formalizam kao naučna, umetnička i filozofska koncepcija bazirana je na tome da je zadatak umetnosti proizvodnja formalnih (nereferencijalnih) 
i autonomnih struktura. Taktike formalizma oslanjaju se na modernističko postkantovsko uverenje da su područja ljudskog saznanja autonomna i da ne zavise od zakona prirode ili ljudskog iskustva, već od jezičkih i logičkih pravila, uz pomoć kojih se upravlja ljudskom spoznajom (filozofija, nauka, teorija). Za razliku od visokog modernizma po kome umetničko delo nastaje estetskom redukcijom izgleda i zamisli umetničkog dela, ruski formalizam imao je lingvističko-semiotičko uporište po kojem je umetničko delo jezički (lingvističko-semiotički) sistem elemenata i nastaje kao proces njihovog povezivanja.

Viktor Šklovski suštinu umetničkog dela vidi u ,sumi njegovih stilskih postupaka" i umetnost posmatra kao vanemocionalnu aktivnost. On zastupa mišljenje da je umetnost ,čista forma”, kao i da umetničko tkivo dela čine odnosi u književnom materijalu. Ono što je rusku formalističku školu činilo specifičnom (iako su Šklovski, Tinjanov, Ejhenbaum išli svojim putem i svako se na tom putu menjao) jeste početna pozicija svakog od formalista: $\mathrm{u}$ formulisanju problema poetike nastojalo se da se umesto filozofije, psihologije itd. (sa kojima je bila povezana tradicionalna nauka o književnosti) orijentiše na lingvistiku, na metode čisto filološke analize umetničkog dela, odnosno na konkretno proučavanje književne građe. U tom smislu ruski formalisti insistirali su na potpunoj izolaciji građe umetničkog dela. Šklovski je preko koncepcije umetnosti kao postupka pokušavao da (de)montira mehanizam unutrašnjeg sklopa književnog teksta i njegovu jezičko-ritmičku organizaciju. Kočenje govornog medijuma, odnosno niza u poeziji, razbijanjem njegovih govornih sekvenci, čini da se umetnički objekat konstruiše preko viđenja, a ne prepoznavanja.

Da bi se vratilo osećanje života, da bi se stvari osetile i kamen postao kamen, postoji ono što se zove umetnost. Cilj umetnosti je da se osećanje stvari da preko viđenja, a ne prepoznavanja: umetnički postupak je postupak oneobičavanja stvari, postupak otežane forme koji potencira teškoće i vreme trajanja percepcije, jer je taj proces u umetnosti sam sebi cilj i mora biti produžen. (...) Iskrivljen put, put na kojem noga oseća kamenje, put koji se vraća unazad - to je put umetnosti (Šklovski, 1985, 361).

Kada govori o otežanom putu, Šklovski misli na otežanu mogućnost oseta književnog postupka, odnosno njegove formalne konstrukcuje, a ne njegove sadržine. Osetnost umetničkog dela poseduje samostalnu umetničku vrednost: „Nova forma ne javlja se da izrazi novu sadržinu, već da 
zameni staru formu koja je već izgubila svoj umetnički karakter" (Šklovski, 1985, 361). Viđenje umetničke strukture, a ne njeno prepoznavanje metodološki predlaže i Kručonih u svom manifestu Reč kao takva iz 1913. godine. On piše o umetničkom delu kao čistoj formalnoj strukturi nezavisnoj od prirode ili njenog odraza. Po Kručonihu umetničko delo predstavlja formalistički nezavisnu, slobodnu konstrukciju, on piše:

4. Misao i govor ne mogu se uhvatiti emocionalnim iskustvom nečije inspiracije; zato je umetnik slobodan da se izrazi ne samo zajedničkim jezikom (koncepti), već i privatnim (stvaralac je individua), kao i jezikom koji ne poseduje konačno značenje (nije zamrznut), a koji je transracionalan. Zajednički jezik je obavezujući, a slobodni dozvoljava potpuniji izraz (...). Nove verbalne forme stvaraju novi sadržaj, a ne obrnuto (Kručonih prema Markov, 1968, 131).

Zaumnost je po formalistima sadržana i u montažnom postupku. Ono što su zaumni pesnici formalno primenili u konstruisanju svog poetskog eksperimenta bio je postupak montaže. O zaumu i principu montaže pisao je Boris Ejhenbaum u delu Književnost i film:

Prvobitna priroda umetnosti jeste potreba za iskorišćavanjem i organizacijom onih energija čovekovog organizma koje se isključuju iz uobičajenog načina života ili dejstvuju u njemu delimično, jednostrano. To i jeste njena biološka osnova, koja pokazuje silu životne potrebe što traži zadovoljenje. Ta osnova, po suštini igralačka i nevezana sa određeno izraženim „smislom”, otelovljuje se u onim „zaumnim”, ,samociljnim” tendencijama koje se naziru u svakoj umetnosti i pokazuju se kao njeni organski fermenti. Korišćenjem i pretvaranjem tog fermenta u ,izražajnost” organizuju se umetnost kao socijalna pojava, kao ,jezik” naročite vrste. Ove „samociljne” tendencije se ponekad obnažuju i postaju parola umetnika-revolucionara - tada počinju govoriti o ,zaumnoj poeziji”, o ,apsolutnoj muzici”, i dr. U stalnom neslaganju ,zaumnosti” i ,jezika” jeste unutrašnja dijalektika umetnosti, koja upravlja njenom evolucijom (Ejhenbaum, 1972, 147-148).

Ejhenbaum se zalagao za konstruktivni metod formalističke škole $\mathrm{i}$ isticao je da su formalisti protiv mešanja nauke i problema spekulativne estetike. On se zalaže za specifikaciju i konkretizaciju književnog proučavanja, te je sa tim dominiralo njegovo interesovanje za pitanje konstrukcije, rasporeda, funkcionisanja elemenata umetničkog dela. Naročito je isticao da formalistička škola istupa protiv simbolističke škole shvatanjem forme, a to je izložio u svojoj teoriji „formalnog metoda” iz 1925. godine:

Pojam „forme” se javio u novom značenju, ne kao omotač, već kao punoća, kao nešto konkretno - dinamično, sadržajno samo po sebi, izvan svih uzajamnih odnosa. U tome 
se ispoljavalo odlučno odstupanje od principa simbolizma, po kojima se „kroz formu” moralo nazreti nešto „sadržajno”. Isto tako se savlađivao i „estetizam”, kao zanošenje nekim elementima forme koji su svesno odvojeni od „sadržine” (Ejhenbaum, 1972, 16).

Montaža znakova/slova kao osnovni sintaksički plan zaumnih pesničkih konstrukcija predstavljala je i genezu i konstrukciju zaumnog teksta. Kao konstitutivno načelo montaža omogućava da metapoetika zauma nastane spajanjem već gotovih ili modifikovanih različitih govornih celina. Konstruisanje zaumnog teksta preko montažnog načela omogućava izgradnju velikog zaumnog heterogenog sastava u kome dolazi ne do deduktivnog misaonog procesa, koji komponuje zatvorenu misaonu celinu unutar pesničke konstrukcije, već do induktivnog misaonog procesa koji polazi od ravnopravnih i samostalnih fragmenata jezičkih izgovorenih sklopova prema otvorenoj pesničkoj celini. Zaumni tekst iz perspektive montažne konstrukcije predstavlja sastav građen od potencijalno beskrajnog niza jezičkih podsastava koji omogućavaju simultanu prezentaciju raznorodnih stilskih i genetskih govornih materijala. U takvom nizu zaumnih autonomnih fragmenata smenjuju se poetski genealoški materijali, parafilološki iskazi i aksiomi. Montažni princip pružio je između ostalog mogućnost zaumnim pesnicima da demonstriraju neološke postupke ${ }^{1}$. Flaker naglašava da je montažni princip bio ključan u pesništvu Hlebnjikova:

Hlebnikovljevo je „neimarstvo” u građenju većih celina od fragmenata vlastitog dela koji i dalje zadržavaju svoju ,autonomnost” (...), pa celina ostaje „otvorenom”, dopuštajući i veći broj kombinacija - za avangardu vrlo karakteristično (...). Načelo montaže i ovde je došlo u punoj meri do izražaja" (Flaker, 1984, 52).

U tom smislu Flaker kao primer navodi Hlebnjikovljevu pesmu Vidrina deca koja je nastala od malih fragmenata postupkom montaže: „Delo se pojavljuje pred nama kao montaža tematski, stilski i genološki različitih fragmenata, sjedinjenih idejom opšteg jedinstva fragmentariziranog kulturno-povesnog prostora i vremena" (Flaker, 1984, 128).

Put transfiguracije je teoretičare formalizma vodio od mimetičkog teksta, zasnovanog na referenci, u tekst čija je referenca sam proces pisanja. Pisac/umetnik kroz tekst govori transformišući umetnički medij na tekstualnu praksu, reči, sintagme, gramatičke znakove i izvesne logičke

\footnotetext{
${ }^{1}$ Primer: onomatopoetski tip zaumnog jezika Hlebnjikova, tzv. ptičji jezik.
} 
konstrukcije. Samim tim teoretičari formalizma zauzimaju stav da je jezik kao materija umetničkog rada moguć tek kao diskurs višeg reda (metajezik) uz pomoć koga umetnik izlazi iz svakodnevnog okruženja govora, pisanja. Formalistima su futuristički zaumni eksperimenti poslužili kao ogoljeni laboratorijski citati, postavljeni kao objekt umetničkog produkovanja, a koji su ,podigli” na nivo demonstracije šta konstruisanje zapisa umetničkog medija zapravo jeste. Futuristički eksperiment je predstavljao iskorak iz literature (prvostepene diskurzivnosti), koji su formalisti iskoristili kao rad o radu (drugostepena [meta]diskurzivnost), odstranjujući kompleksnost posredničkih uloga reference (npr. futurističko oslanjanje na govor sekti, na prvobitni jezik ljudske zajednice itd). Formalistički modeli konstruisani su na čistoj ontologiji samog procesa konstruisanja umetničkog medija.

Hladnim neemocionalnim pokretanjem elemenata, umetnik kao igrač domina pokreće figure gradeći privremene govorne iskaze i time čini da umetnost egzistira samo kao sopstvena granica. U takvoj igri pisani elementi ostaju nepromenljivi, fiksirani i predstavljaju formalnu strukturu pesme. Izvođenjem forme pesme, odnosno glasovnim pokretanjem fiksirane forme, pokreću se i organizuju nova značenja. Beskonačna pokretljivost pisane forme zaumne pesme produkuje beskonačnost novodolazećih značenja. Formalistički metod i zaumni metod se ukazuju kao konstantno odmicanje od umetnosti, kao ospoljenje same umetnosti u odnosu na nju samu, produkujući konstantno izmicanje distance (tj. mišljenje o umetnosti). Drugim rečima, i formalisti i zaumni pesnici žele da ukažu na one ontološke momente umetnosti koji pokazuju da je umetnost disciplina koja poseduje sopstvene (unutrašnje) moći da proizvodi sebe kao umetnost i kao istoriju umetnosti. Sa druge strane, prepoznajemo upotrebljene elemente stiha (slova), razaznajemo njihovu upotrebu u sasvim drugačijoj funkciji u procesu izvođenja. Takva pesnička naracija nije pripovest, već je naracija od jezika koja gradi atmosferu jezika, umetničkog, odnosno pesničkog objekta. Formalisti su odavno u svom eksperimentu prešli prag jezika naracije. Svet postaje jezik novog narativnog uobličavanja u kome ne postoje istovetnosti i reference, već pretapanje umetničkih fragmenata u projekcije od pesničkog jezika. 


\section{Literatura}

Đurić, D. (2002). Jezik, poezija, postmodernizam: jezička poezija u kontekstu moderne i postmoderne američke poezije. Novi Beograd: Oktoih.

Ejhenbaum, B. (1972). Književnost. Prev. M. Bojić. Beograd: Nolit.

Flaker, A. (1984). Ruska avanagarda. Zagreb: Sveučilišna naklada Liber/Globus.

Flaker, A. (1988). Nomadi ljepote. Intermedijalne studije. Zagreb: Grafički zavod Hrvatske.

Golubović, V. (1985). Zenit/ruska avangarda. U: Pojmovnik ruske avangarde. Prir. A. Flaker, D. Ugrešić, sv. IV. Zagreb: Grafički zavod Hrvatske, str. 163-174.

Hlebnjikov, V. (1964). Kralj vremena Velimir I. Prev. V. Nikolić, B. Ćosić, M. Nikolić. Beograd: Prosveta.

Ivanov, V. (2003). Hlebnjikov i nauka. Prev. R. Mečanin. Beograd: Narodna knjiga/ Alfa.

Latifić, A. (2008). Paradigme ruske avangardne i postmoderne umetnosti. Beograd: Čigoja štampa i Fakultet dramskih umetnosti.

Markov, V. (1968). Russian Futurism: A History. Berkeley-Los Angeles: University of California Press.

Mijušković, S. (prir.). (2003). Dokumenti za razumevanje ruske avangarde. Antologija tekstova umetnika. Beograd: Geopoetika.

Nilsson, N.A. (1990). Velimir Hlebnjikov: ,Zoo”. U: Pojmovnik ruske avangarde. Prir. A. Flaker, D. Ugrešić, sv. VIII. Prev. M. Varga, Zagreb: Grafički zavod Hrvatske, str. 215-226.

Oraić, D. (1985). Zangezi Velimira Hlebnjikova. „Književna reč”, br. 266, 10.11., str. 19.

Solivetti, C. (1985). „Azbuka uma” Velimira Hlebnjikova. U: Pojmovnik ruske avangarde. Prir. A. Flaker, D. Ugrešić, sv. III. Prev. E. Ratković. Zagreb: Grafički zavod Hrvatske, str. 223-233.

Šklovski, V. (1985), Energija zablude. Knjiga o sižeu. Prev. Ž. Đukić. Beograd: Prosveta.

Ziegler, R. (1985). Kručonih, Aleksej. U: Pojmovnik ruske avangarde. Prir. A. Flaker, D. Ugrešić, sv. III. Prev. E. Ratković. Zagreb: Grafički zavod Hrvatske, str. 187-198.

Бобринская, Е. (2000). Футуризм. Москва: Галарт

Бобринская, Е. (2003), Русский авангард: истоки и метаморфозыл. Москва: Пятая страна.

Котович, Т.В. (2003). Энииклопедия русского авангарда. Минск: Экономпресс.

Кручёных, А. (2001). Стихотворения. Поэмы. Романы. Опера. Санкт-Петербург: Гуманитарное агенство «Академический проект».

Поляков, В. (1998). Книги русского кубофутуризма. Москва: Гилея. 